\title{
Influence of solar radiation, microalgal fouling, and current on deposition site and survival of embryos of a dorid nudibranch gastropod
}

\author{
Christiane H. Biermann ${ }^{1}$, Gottfiried O. Schinner ${ }^{2}$, Richard R. Strathmann ${ }^{3, *}$ \\ ${ }^{1}$ State University of New York at Stony Brook, Department of Ecology and Evolution, Stony Brook, New York 11794, USA \\ ${ }^{2}$ University of Alabama at Birmingham, Department of Biology, 1300 University Blvd., Birmingham, Alabama 35294, USA \\ ${ }^{3}$ Friday Harbor Laboratories and Department of Zoology, University of Washington, 620 University Road, Friday Harbor, \\ Washington 98250 , USA
}

\begin{abstract}
Risks associated with benthic development may be reduced by maternal selection of favorable sites for deposition of egg masses. We examined deposition and survival of embryos in relation to potential hazards or benefits from differences in solar radiation, microalgal fouling and current speeds that are associated with macroalgal shading. Submerged egg ribbons of the dorid nudibranch Archidoris montereyensis (Cooper) were laid in the shade of macroalgae more often than by chance alone. In field experiments, more embryos died in submerged sunny than in submerged shady sites. The egg ribbons in shady field sites were less fouled by microalgae and were found in slower currents. In laboratory experiments, either solar radiation or algal fouling could kill embryos, but low flow did not. Defenses against algal fouling were not apparent; in the field more diatoms fouled new egg ribbons than fouled glass microscope slides. Embryos are protected from solar radiation by thickness of an egg mass, and egg ribbons of different species appear to differ in vulnerability to solar radiation. These observations indicate that solar radiation can directly or indirectly limit the distribution of benthic development in shallow water.
\end{abstract}

\section{INTRODUCTION}

Marine biologists have given much attention to larval settlement and selection of favorable benthic sites (Hadfield 1986, Woodin 1986, Morse 1990, Pawlik et al. 1991), but there has been little attention to selection of sites for deposition of benthic eggs, a problem of comparable importance. Benthic development appears to be generally safer than planktonic development (Pechenik 1979, 1986, Strathmann 1985, Rumrill 1990), but this apparent safety depends on parental choice of sites and the often complex extraembryonic structures that protect embryos. Not all benthic situations may be so favorable, and not all animals may be able to produce protective structures that are effective throughout the adults' range of habitat (Giorgi \& Congleton

- Addressee for correspondence
1984, Wilson 1986, Strathmann \& Strathmann 1989). Both the type of parental protection and the availability of safe benthic sites vary greatly among taxa.

Similarly, some potential hazards to benthic embryos have received little attention even though they are widespread. Effects of solar radiation on planktonic larvae and embryos have received more attention (Thorson 1964, Hairston 1979, Damkaer et al. 1981, Hunter et al. 1982, Pennington \& Emlet 1986) than effects of solar radiation on benthic embryos. Microorganisms can kill embryos in crustacean broods and there are defenses against them (Fisher 1983, Bauer 1989, Shields 1990); but, though fouling by microbial eukaryotes is known for egg masses that are not brooded (Burggren 1985, Takano 1985), the effects of microbial fouling on the embryos in marine benthic egg masses are poorly known.

In this study we examined benefits and hazards from macroalgal shading of gelatinous egg ribbons in shal- 
low water and addressed both maternal selection of deposition sites and survival of embryos. We picked the dorid nudibranch Archidoris montereyensis because the adults are mobile and therefore have some capacity to select among sites for egg deposition. Another reason for our choice of species was that these animals produce resilient egg ribbons (Hurst 1967) of high surface area (ca $2 \mathrm{~cm}$ wide and $<1 \mathrm{~mm}$ thick; Fig. 1A) so that problems of adhesion and gas exchange are likely to be slight. Also many nudibranchs, including A. montereyensis (Gustafson \& Andersen
1985), contain compounds distasteful to predators, and this defense extends to some dorid egg masses (Pawlik et al. 1988). There were no indications of predation on the egg ribbons of $A$. montereyensis and that eliminated a potentially complicating factor.

Our objectives were to determine whether eggs are preferentially deposited in favorable sites and to test the importance of 3 environmental factors for survival and developmental rate of embryos: solar radiation, fouling by microalgae and currents. Tests included both field and laboratory experiments.
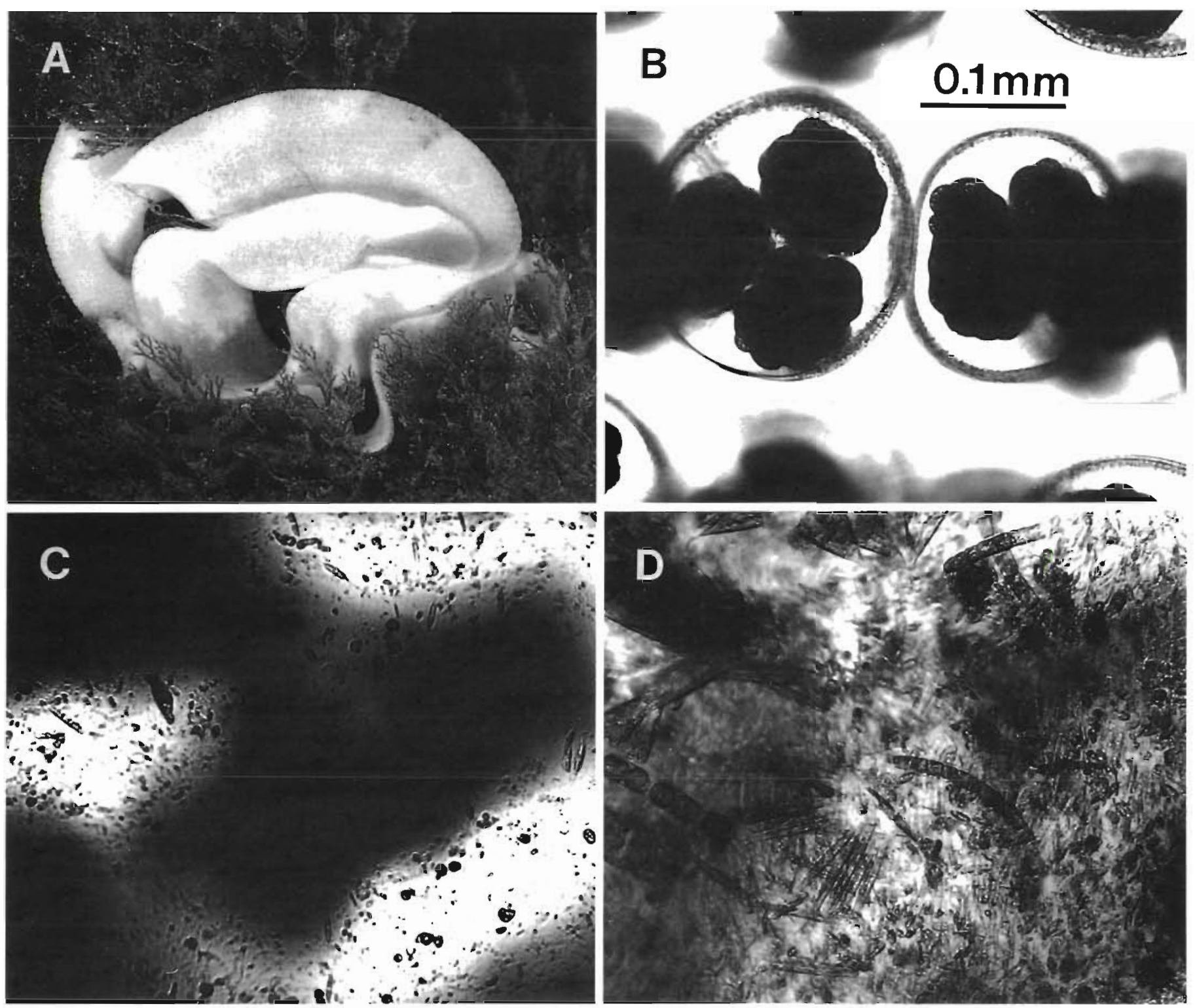

Fig. 1. Archidoris montereyensis. Egg ribbons. (A) Whole ribbon in Argyle Creek; (B) encapsulated embryos within the gelatinous ribbon; (C) lightly fouled surface of an egg ribbon; (D) heavily fouled surface of an egg ribbon. See text for approximate size of a whole ribbon in (A). The scale is the same for (B), (C), and (D). Dark areas in (C) and (D) are out of focus embryos 

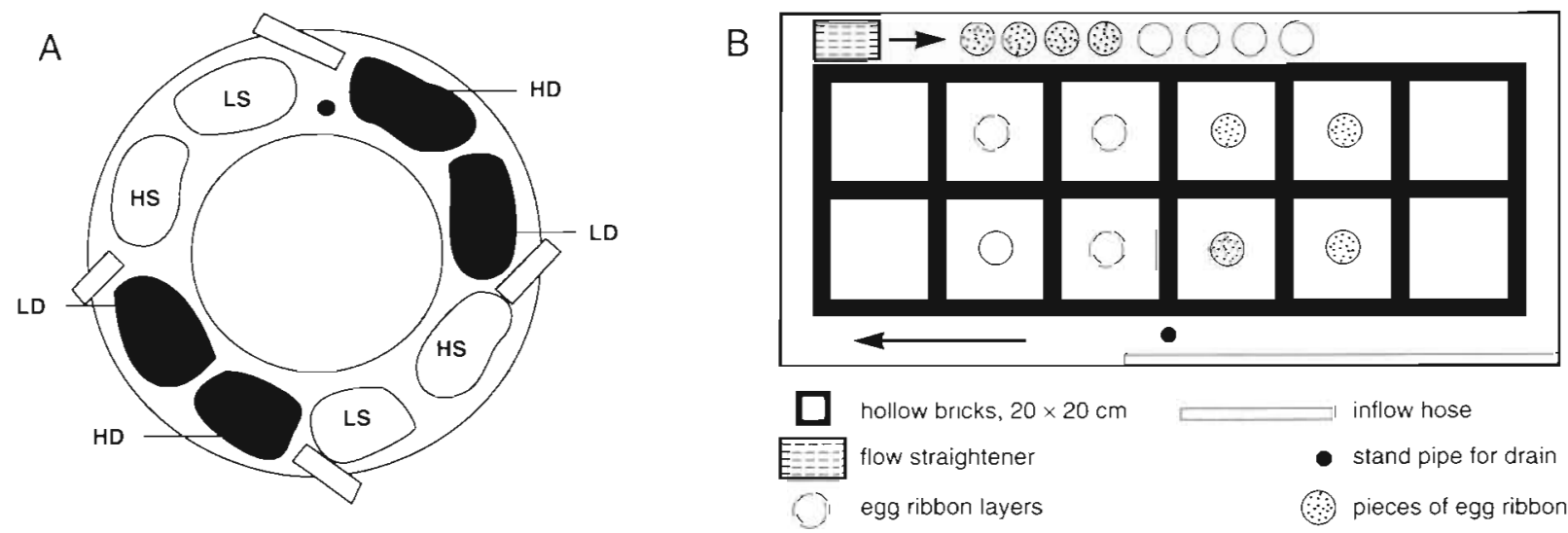

inflow hose

stand pipe for drain

Fig. 2. (A) Diagram of treatments in a circular flume for test of deposition at shaded and unshaded sites. LD: low current, dark; LS: low current, sun; HD: high current, dark; HS: high current, sun. (B) Diagram of treatments in a rectangular tank for testing effects of current and of layering of egg ribbons

\section{MATERIALS AND METHODS}

Study site. The experiments were conducted from May to August 1991 at the Friday Harbor Laboratories (FHL) on San Juan Island, Washington, USA. The field site was a tidal creek on the southeast side of the island connecting Argyle Lagoon (ca $48^{\circ} 31^{\prime} \mathrm{N}, 123^{\circ} 01^{\prime} \mathrm{W}$ ) with the more open waters of North Bay (off San Juan Channel, to the north of Puget Sound). This small tidal channel has an extended period of steadily ebbing current with depths averaging $<20 \mathrm{~cm}$ during daytime low tides at a season of long days (May to August). The creek bed is composed of gravel and small rocks and is never exposed to air. Patches of macroalgae, mostly species of Ulva, Ceramium, and Prionitis, provide abundant shade at the upper end of the creek and patchy shade elsewhere. In June and July the water temperatures were about 17 to $18^{\circ} \mathrm{C}$ during the daytime flow out of the lagoon. The nightly flood tide that preceded higher high water brought water of 13 to $15^{\circ} \mathrm{C}$ into the creek in a briefer but stronger flow from North Bay. Laboratory aquarium temperatures were lower, about 11 to $13^{\circ} \mathrm{C}$ when there was continuous renewal of sea water. Day lengths were 14 to $16 \mathrm{~h}$, and the weather was mostly sunny. There were no negative results that could be attributed to cloudy days.

Selective deposition of egg ribbons. The hypothesis that adults of Archidoris montereyensis preferentially lay their eggs underneath macroalgae in Argyle Creek was tested by sampling a mid-part of the channel in which macroalgae formed small patches. Quadrats of $120 \times 60 \mathrm{~cm}$ were placed contiguously over this part of the creek, and for quadrats containing egg masses ( $n=16$ ), algal cover was determined by presence or absence on $10 \mathrm{~cm}$ grid points. Numbers of shaded and unshaded egg masses were noted.
Current speeds were measured at 12 egg ribbons and at nearby sites ( $60 \mathrm{~cm}$ away) perpendicular to the direction of the current. We held an electromagnetic flow meter (Marsh-McBirney Inc., MD, USA; Model 511) next to an egg mass and again at an equal distance from the bottom at the matching unsheltered site.

To test for selective deposition between shade and sunlight and between full and obstructed currents in the absence of biological properties of macroalgae, a circular flume with a cobbled bottom was built, offering high and low water speed and 2 light regimes in continuously renewed flowing water (Fig. 2A). Diameters were $1 \mathrm{~m}$ for the outer wall and $0.55 \mathrm{~m}$ for the inner wall. Shelters were constructed of $15 \times 30 \mathrm{~cm}$ black and clear polyethylene plastic sheets attached to wire wickets at both ends and covered most of the bottom of the flume. Four equally spaced inflow pipes provided the fast current treatments, and the upstream wire was replaced by a barrier of plexiglass for the low current treatments, so that each half of the flume had all 4 combinations of dark and clear plastic sheets and fast and slow currents. The flume was outdoors with open top and with walls transparent to visible light but of thick acrylic plastic, which absorbs ultraviolet light. Fourteen adults of Archidoris montereyensis were collected in Argyle Creek and kept in the tank for $6 \mathrm{~d}$. They were fed with their natural food, the sponge Halichondria sp.

Effects of macroalgal shelter. Effects of macroalgal shelter were tested in 2 field experiments. In the first experiment (mid-May), 3 egg masses of Archidoris montereyensis that had been laid on more than 1 pebble were split. Half of each mass was moved into an area exposed to full sun and current and half was replaced under the original macroalgal shelter. In the 
second experiment (mid June), both halves were moved, 1 under a macroalga, 1 to an exposed site. The 2 pieces were not more than $30 \mathrm{~cm}$ apart. Subsamples of the ribbons were removed to check for developmental stage (initially at or before gastrula; Fig. 1B) and initial percent survival (close to $100 \%$ ). After $5 \mathrm{~d}$ (first experiment) or $7 \mathrm{~d}$ (second experiment), survival and stage of development of embryos were estimated by sampling transects across the ribbon (more than 20 sites at $1 \mathrm{~mm}$ intervals in the first experiment and 5 sites in each of 3 transects in the second experiment). Survival was estimated for embryos in capsules closest to each sampled point. (There were 2 to 6 embryos per capsule in egg ribbons from Argyle Creek.) Developmental stages, ranked as in Table 1, were estimated as the mean stage for surviving embryos. Microalgal fouling on the gel surface (Fig. 1C, D) was assessed by replicate counts (5 per ribbon in Experiment 1, 15 per ribbon in Experiment 2) of all diatoms and other algal cells intersected by the ocular scale bar with a $40 \times$ objective lens in Experiment 1 and with a $10 \times$ objective in Experiment 2. (Cell counts were lower at lower power but adequate for comparisons within experiments.) Within both experiments, higher counts of algal cells were clearly associated with a greater percent cover by algal cells.

Table 1. Archidoris montereyensis. Ranking of developmental stages of encapsulated embryos for statistical comparisons

\begin{tabular}{|c|c|c|c|}
\hline Rank & Stage & Rank & Stage \\
\hline 1 & Uncleaved egg & 8 & Gastrula \\
\hline 2 & 2 cells & 9 & Trochophore \\
\hline 3 & 4 cells & 10 & Veliger with minute \\
\hline 4 & 8 cells & & shell \\
\hline 5 & 16 cells & 11 & Veliger with cup- \\
\hline 6 & 32 cells to blastula & & shaped shell \\
\hline 7 & Blastula & 12 & $\begin{array}{l}\text { Veliger with coiled } \\
\text { shell }\end{array}$ \\
\hline
\end{tabular}

Separate effects of shade and current. Macroalgae shelter the egg masses from both sun and current. To test the effect of shade with no difference in current, the ends of $15 \times 35 \mathrm{~cm}$ plastic sheets were taped to $U$ shaped $3 \mathrm{~mm}$ steel wires that were then pushed into the gravel in Argyle Creek just upstream of egg masses and with about $10 \mathrm{~cm}$ space for water to flow beneath the plastic sheets. Egg ribbons were divided into thirds for 3 treatments: a wire wicket with a black plastic sheet, a wire wicket with a clear plastic sheet, and a wire wicket only. The 3 treatments for each egg mass were set up next to each other and it was confirmed with the flow meter that they experienced equal current speeds. The 5 replicates were distributed near mid-channel of the tidal creek. The experiment lasted $5 \mathrm{~d}$. Counts of fouling microalgae were with a $40 x$ objective lens.

The effect of water movement on embryonic development was examined in the laboratory by cutting a freshly laid egg ribbon into pieces divided into 2 treatments: a current of $18 \mathrm{~cm} \mathrm{~s}^{-1}$ and nearly still water. For these treatments an experimental tank with continuously renewed flowing water was partitioned by cement blocks into a peripheral channel with the current and a central area with still water (Fig. 2B). The blocks were elevated 1 to $2 \mathrm{~mm}$ from the bottom to allow some renewal of the water into the central area. Outer dimensions of the tank were $1.2 \times 0.6 \mathrm{~m}$. The temperature was $11^{\circ} \mathrm{C}$. The beginning stage was prior to first cleavage and each experiment was with pieces from a single egg ribbon. For one experiment each of the 4 replicates in each treatment was composed of a single layer of egg ribbon. For a second experiment that tested the influence of egg mass thickness, each of the 4 replicates per treatment was composed of 4 layers of a different egg ribbon. The pieces of egg ribbon were held in place by insect pins on parafilm sheets wrapped around watchglasses. The developmental stages of all embryos in 10 capsules in the central part of each single piece and each layer in the egg ribbon stacks were noted after $12 \mathrm{~d}$ for the first experiment and after $11 \mathrm{~d}$ for the second experiment.

To investigate the effect of current speed on flow past surfaces of egg ribbons, we observed movement of fluorescein dye around several Archidoris montereyensis egg ribbons in a flow tank (Vogel \& LaBarbera 1978) in currents of 1.5 to $50 \mathrm{~cm} \mathrm{~s}^{-1}$. Intact coils were compared to ones that had been cut vertically.

Effects of solar radiation. In order to test effects of solar radiation on egg ribbons without differences in algal fouling, we placed fragments of egg ribbons with early stage embryos into open glass bowls in $2 \mathrm{~cm}$ of water outdoors in a water-cooled trough at 12 to $15^{\circ} \mathrm{C}$ (varying during the day). One piece of each ribbon was in direct sunlight for most of the day and another piece in full shade from a black plastic cover. The experiment ran for 1 full day of solar radiation and included the preceding and following nights. Egg ribbons were then maintained for $2 \mathrm{~d}$ in shade to determine subsequent survival while preventing differences in microalgal fouling. Because shaded embryos had reached gastrula or trochophore stages, embryos arrested in early cleavage stages were counted as dead. Counts of fouling microalgae in this and in subsequent experiments were with a $10 \times$ objective lens.

Effects of microalgal fouling. In order to test for effects of microalgal fouling without a lethal dose of solar radiation, we placed ribbons in $100 \mathrm{ml}$ beakers in a water cooled trough in a south facing window for 10 
or $11 \mathrm{~d}$ (with the additional day for the 2 replicate groups that started at an earlier stage). The window glass, beaker glass, and a $5 \mathrm{~mm}$ thick sheet of acrylic plastic were expected to block ultraviolet light (and proved sufficient to prevent mortality in the absence of dense microalgal fouling). An end of each fragment of ribbon was clipped into an incision in a platform of plastic mesh of $4 \mathrm{~mm}$ openings above an aerating bubble stream so that both sides of the egg ribbons were exposed to a continuous flow of air saturated water. Each ribbon was divided into 4 treatments for all 4 combinations of light versus dark and of natural sea water versus sea water enriched with nutrients for algal growth. The nutrient enrichments were $75 \mathrm{mg} \mathrm{l}^{-1}$ $\mathrm{NaNO}_{3}, 5 \mathrm{mg} \mathrm{l} \mathrm{l}^{-1} \mathrm{NaH}_{2} \mathrm{PO}_{4} \cdot \mathrm{H}_{2} \mathrm{O}$, and $30 \mathrm{mg} \mathrm{l^{-1 }}$ $\mathrm{Na}_{2} \mathrm{SiO}_{3} \cdot 9 \mathrm{H}_{2} \mathrm{O}$, as in commonly used media for culturing microalgae (Guillard 1983). As a control for effects of the nutrient stock other than the enrichment, a volume of deionized water equal to the volume of the enrichment stocks $(0.8 \mathrm{ml})$ was added to the treatment with natural sea water. Water was changed daily. For the first several days a mixed microalgal population (mostly diatoms) from an aquarium was added to all beakers as an inoculation. A separate experiment of 8 to $10 \mathrm{~d}$ and with only light and dark treatments with natural sea water confirmed that intensities and frequencies of light in this apparatus were insufficient to kill the embryos. An alternative method, in which germanium dioxide was used to inhibit diatom growth (Lewin 1966), was not successful because $10 \mathrm{mg}$ of $\mathrm{GeO}_{2} 1^{-1}$ affected development of the embryos.

Fouling of egg ribbons and glass was compared in the field by clipping the ends of an egg ribbon and an ethanol cleaned glass microscope slide into a pair of incisions in a flexible plastic tube and fastening the tube upon the bottom of the tidal channel by stiff wires driven through the tube and into the gravel substratum.

\section{RESULTS}

\section{Selective deposition of egg ribbons}

In the quadrats in the tidal creek, more Archidoris montereyensis egg ribbons were shaded by macroalgae than by chance alone. The test compared the number of egg ribbons in shade (21.5) and sunlight (16.5) to the proportion of the area shaded by seaweeds. (One egg ribbon was half in shade, hence the fractional count.) For 16 quadrats the mean and standard deviation (SD) for the proportion of egg masses shaded by algae was $0.51( \pm 0.42)$, whereas the mean and SD for the proportion of substratum shaded by algae was $0.24( \pm 0.14)$. The proportion of egg masses shaded was significantly different from the proportion of substratum shaded $(G=14.9 ; \mathrm{p}<0.005)$. Deposition was not under a single type of seaweed. Ribbons were found under and on the undersides of Ulva sp., Ceramium sp., and Prionitis lyallii.

Seaweeds changed the environment of embryos in 3 obvious ways. (1) Egg ribbons under macroalgae were more shaded. (2) Egg ribbons under macroalgae were less fouled by microalgae. They remained whitish or cream-colored (as in Fig. 1A) even when embryos had reached the veliger stage, whereas egg ribbons in full sunlight became brown with a coating composed mostly of diatoms (as in Fig. 1D). (3) Egg ribbons under macroalgae were exposed to slower currents, at least during the predominant ebbing flow. The current velocity at 12 shaded egg ribbons was significantly lower than at 12 nearby places in the tidal creek that were not sheltered by macroalgae (paired $t$-test; $p<$ $0.0001)$. The mean and SD for current velocity at the shaded egg masses was $2.9( \pm 1.4) \mathrm{cm} \mathrm{s}^{-1}$ in contrast to $15.4( \pm 5.0) \mathrm{cm} \mathrm{s}^{-1}$ at equivalent unshaded sites. These 3 factors could affect favorability of the deposition site and could also be among the stimuli influencing selection of sites for egg deposition, and in the remainder of the study we concentrated on these 3 factors.

A laboratory experiment indicated that the preference appears to be for shade rather than for lower current speed or some property of the macroalgae. In a circular flume, 11 out of 15 egg masses were laid directly under black plastic covers (mostly on the underside of the plastic). The remainder were not in shade but not all under clear plastic either. This number of egg ribbons is significantly different from the expectation for random laying in the shaded and unshaded areas (5.7 out of $15 ; G=7.6 ; p<0.01$ ). This expectation gave a conservative test, in that the flume walls were not included as potential sites when the proportions of shaded and unshaded areas of the bottom were calculated, and the unshaded eggs that were not laid under clear plastic were included in the comparison. However, the deposition of egg ribbons was aggregated in space and varied in time. The 11 egg masses in the shade were deposited under only 2 of the 4 black plastic shelters: 7 in slow current and 4 in one of the shaded fast current treatments. Because the adults aggregate (perhaps for mating), the ribbons were not deposited independently.

\section{Effects of macroalgal shelter}

Deposition under algal cover increased survival and rate of development of embryos and decreased microalgal fouling of the surface of egg ribbons. In 2 experiments egg ribbons were split and half placed under 
Table 2. Archidoris montereyensis. Effects of macroalgal shelter on survival and developmental stage of embryos and microalgal fouling of egg ribbons. Each ribbon (numbered in the table) was divided between a site shaded by macroalgae and a site exposed to full current and sunlight. Fouling by microalgae is number of cells intersected by transect lines sampling one side of the ribbon. Developmental stages ranked as in Table 1

\begin{tabular}{|c|c|c|c|c|c|c|}
\hline \multirow[t]{2}{*}{ Egg ribbon } & \multicolumn{2}{|c|}{ Proportion surviving } & \multicolumn{2}{|c|}{$\begin{array}{l}\text { Microalgal fouling } \\
\quad\left(\text { cells } \mathrm{mm}^{-1} \text { ) }\right.\end{array}$} & \multicolumn{2}{|c|}{ Stage of embryos } \\
\hline & Shaded & Unshaded & Shaded & Unshaded & Shaded & Unshaded \\
\hline \multicolumn{7}{|l|}{ Experiment 1} \\
\hline 1 & 0.75 & 0.37 & 34 & 82 & 11.0 & 9.5 \\
\hline 2 & 1.00 & 0.64 & 16 & 64 & 12.0 & 10.0 \\
\hline 3 & 1.00 & 0.79 & 2.8 & 100 & 11.5 & 9.5 \\
\hline \multicolumn{7}{|l|}{ Experiment 2} \\
\hline 1 & 0.96 & 0.43 & 11 & 39 & 11.4 & 9.7 \\
\hline 2 & 1.00 & 0.77 & 6.7 & 40 & 12.0 & 11.7 \\
\hline 3 & 0.84 & 0.34 & 21 & 37 & 11.4 & 11.0 \\
\hline 4 & 1.00 & 0.35 & 8.6 & 37 & 11.2 & 9.6 \\
\hline
\end{tabular}

macroalgae, half in full exposure to sun and current. All embryos were at gastrula stage or earlier at the start of the experiment, and the most advanced embryos were at veliger stage at the end. In 7 out of 7 cases the portion of egg ribbon in full sunlight and full current had lower survival, less advanced embryos, and more fouling by microalgae (Table 2). These effects of macroalgal shelter are significant at $p=0.016$ by a sign test, whose paired comparisons are not affected by differences in period of exposure, weather, and sampling methods in the 2 experiments.

Partial shading contributed to variation within shaded ribbons. For example, in the first shaded ribbon of Experiment 1 (Table 2), part of the transect for estimating survival fell in a part of the egg ribbon with much higher mortality and heavier microalgal fouling than the rest of the ribbon, which had low mortality and fewer microalgae.

Fouling by microalgae was associated with greater embryo mortality and retardation of development. In this experiment and in all subsequent observations of microalgal fouling, the microalgae were predominantly diatoms, though of diverse forms (Fig, 1C, D). There were only a few green filaments and rarely red algal cells. The mobile ciliates and metazoans were not counted but were also much scarcer than diatoms. Only the diatoms were so abundant that their metabolic activity might affect the environment of embryos.

To confirm that survival in egg ribbons was low without macroalgal cover, we located several egg ribbons with embryos at the gastrula stage or earlier (on 4 and 6 July) and kept each egg ribbon free of shade from nearby macroalgae for 5 or $6 \mathrm{~d}$ without moving them from the site of deposition and without the structural change otherwise incurred by splitting. Mean survival was 0.30 (range 0 to 0.58 ) and algal fouling was 58 cells $\mathrm{mm}^{-1}$ (range 48 to 65 cells $\mathrm{mm}^{-1}$ ).
We also examined egg ribbons with veliger stage embryos that were exposed to the sun at the time of collection ( 5 on 2 July and 1 on 11 July). The mean survival of these embryos was 0.80 with a range from 0.36 to 1.0 . The mean algal fouling was 47 cells $\mathrm{mm}^{-1}$ with a range of 22 to 65 cells $\mathrm{mm}^{-1}$. In this sample of 6 egg ribbons, the survival was higher than in the 5 egg ribbons that were kept exposed to sun from an early stage ( $p=0.01$, Mann-Whitney rank test) yet the microalgal fouling was not significantly different. We did not know the entire history of the egg ribbons collected at advanced stages, and they could have had less exposure to solar radiation than the egg ribbons that we kept free of macroalgal shade for most of their development.

\section{Separate effects of shade and current}

Differences in currents were excluded as a potential cause of the differences in mortality by dividing egg ribbons into thirds and placing each third under black polyethylene plastic sheets (as artificial macroalgae), under clear polyethylene, or under no cover in Argyle Creek. Mortality of embryos was significantly different among treatments (Tables $3 \& 4$ ) and was less under the black plastic than under the clear plastic or at entirely unsheltered sites (Table 3). Survival was not significantly different between clear plastic sheets and no sheets, but survival under black plastic sheets was significantly different from either of these controls (Scheffé multiple comparison test on the arcsine transformed data, $p<0.05$ ). Again, embryo mortality was associated with sunlight and with diatom fouling.

Effects of current speed on rates of development were tested in the laboratory (Fig. 2B). There was no difference in developmental rate between pieces of 
Table 3. Archidoris montereyensis. Survival of embryos and microalgal fouling of egg ribbons divided among sites under black plastic (black), clear plastic (clear) and no cover (none)

\begin{tabular}{|c|c|c|c|c|c|c|}
\hline \multirow[t]{2}{*}{ Egg ribbon } & \multicolumn{3}{|c|}{ Proportion surviving } & \multicolumn{3}{|c|}{ Microalgal fouling (cells $\mathrm{mm}^{-1}$ ) } \\
\hline & Black & Clear & None & Black & Clear & None \\
\hline 1 & 1.00 & 0.19 & 0.12 & 20 & 84 & 55 \\
\hline 2 & 0.96 & 0.81 & 0.82 & 40 & 110 & 133 \\
\hline 3 & 1.00 & 0.35 & 0.15 & 14 & 84 & 102 \\
\hline 4 & 0.91 & 0.67 & 0.34 & 71 & 91 & 122 \\
\hline 5 & 0.90 & 0.57 & 0.20 & 90 & 116 & 138 \\
\hline Mean & 0.95 & 0.52 & 0.33 & 47 & 97 & 110 \\
\hline $\mathrm{SD}$ & 0.05 & 0.25 & 0.29 & 33 & 15 & 34 \\
\hline
\end{tabular}

Table 4. Archidoris montereyensis. ANOVA for survival of embryos in the 3 treatments of Table 3 (data arcsine transformed)

\begin{tabular}{|lrccc|}
\hline Source & df & Mean square & $F$ & $p$ \\
\hline Between groups & 2 & 1.33708 & 15.40 & 0.0005 \\
Within groups & 12 & 0.08681 & & \\
\hline
\end{tabular}

egg ribbons kept in high water velocity $\left(>15 \mathrm{~cm} \mathrm{~s}^{-1}\right)$ and in nearly still water though development was slow under the experimental conditions with embryos in both treatments developing from the 1 -cell stage into a motile trochophore in $12 \mathrm{~d}$ at about $11^{\circ} \mathrm{C}$.

Because both current and damage to ribbons can affect layering of ribbons (see below), effects of stacking of ribbons were also tested. Stacking of egg ribbons to form a thicker layer resulted in a significant retardation of development both in the fast current and in the nearly still water (Table 5, Fig. 3). The slower development in the lower layers was highly significant (Table 5) despite variation within those layers. The greater retardation of the lower layers in still water (Fig. 3) is expressed by the significant interaction term in Table 6. Development of all embryos was slow in this experiment, but the results suggest that differences in water speed would have a greater effect on development rates for embryos at the same concentration but in layered or thicker egg masses.

Fast currents do not necessarily increase flow past all surfaces of the intact egg ribbons. In a flow tank the ribbon coil stood upright only at very low current velocities $\left(<5 \mathrm{~cm} \mathrm{~s}^{-1}\right)$, in which it waved slowly and regularly. Fluorescein dye released within the ribbon coil moved out of the ribbon in a spiral motion towards the center in less than $1 \mathrm{~min}$. At higher velocities, the coil folded over so that several layers of ribbon were pressed together. Exchange of water between the folds with the water outside was largely blocked, and the dyed water stayed in the folds for several minutes.
Table 5. Archidoris montereyensis. Two-way ANOVA table of experiments on stacked egg ribbons with current (still water or flow) and ribbon layers as factors and stage of development as the measured dependent variable. Stage of development was rank-transformed for normality (Conover \& Iman 1981)

\begin{tabular}{|lrrrl|}
\hline Source & df & Mean square & \multicolumn{1}{c|}{$F$} & $\mathrm{p}$ \\
\hline Current & 1 & 16.5313 & 0.80 & 0.38 \\
Layer & 3 & 582.9792 & 28.24 & 0.0001 \\
Current $\times$ Layer & 3 & 149.3438 & 7.23 & 0.0013 \\
Error & 24 & 20.6458 & & \\
\hline
\end{tabular}

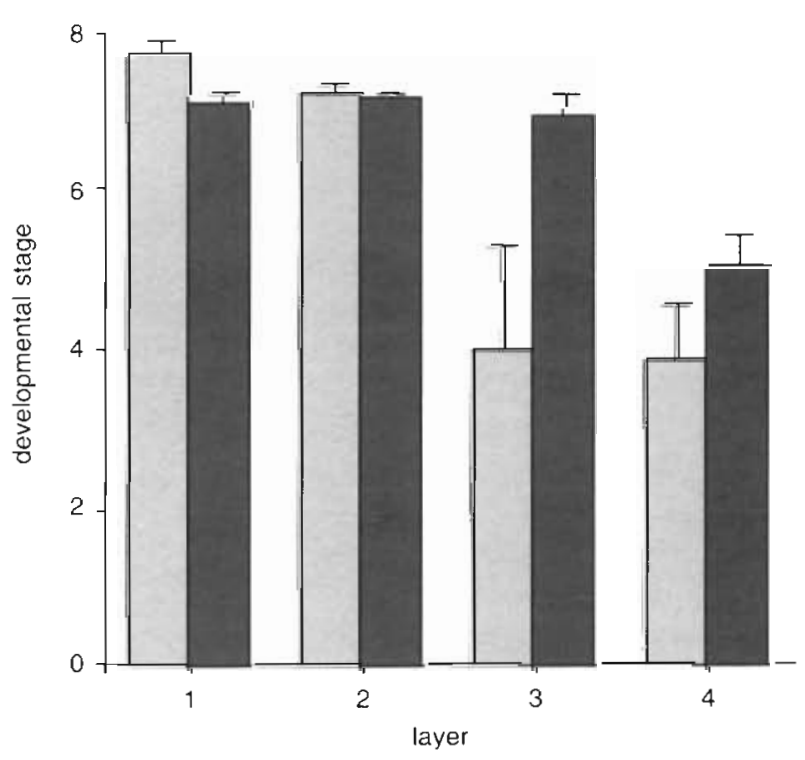

Fig. 3. Archidoris montereyensis. Mean and SE of developmental stages of embryos in egg ribbons stacked 4 layers deep and exposed to flowing water $\left(>15 \mathrm{~cm} \mathrm{~s}^{-1}\right.$ ) or nearly still water in the laboratory. Layers 1 to 4 are top to bottom. Light bars: nearly still water; dark bars: flowing water

The upright position of a coiled egg ribbon depended on the integrity of the coil. Vertical cuts in an egg ribbon resulted in bending of more than $45^{\circ}$ in still water, and very irregular behavior in a current. 
Table 6. Archidoris montereyensis. Survival of embryos and microalgal fouling following exposure of egg ribbons to sun and shade at $2 \mathrm{~cm}$ water depth for $1 \mathrm{~d}$ and subsequent development in the shade for $2 \mathrm{~d}$

\begin{tabular}{|c|c|c|c|c|c|c|}
\hline \multirow[t]{3}{*}{ Egg ribbon } & \multicolumn{4}{|c|}{ Sun vs shade } & \multirow{2}{*}{\multicolumn{2}{|c|}{$\begin{array}{c}\text { Upper vs lower side of ribbons in sur } \\
\text { Proportion surviving }\end{array}$}} \\
\hline & \multicolumn{2}{|c|}{ Proportion surviving } & \multicolumn{2}{|c|}{$\begin{array}{l}\text { Microalgal fouling } \\
\text { (cells } \mathrm{mm}^{-1} \text { ) }\end{array}$} & & \\
\hline & Shade & Sun & Shade & Sun & Lower & Upper \\
\hline 1 & 1.00 & 0 & 1.8 & 3.4 & 1.00 & 0 \\
\hline 2 & 0.95 & 0.36 & 4.8 & 4.7 & 1.00 & 0 \\
\hline 3 & 1.00 & 0.09 & 5.5 & 3.6 & 0.77 & 0 \\
\hline 4 & 0.97 & 0 & 7.3 & 9.3 & 0.77 & 0 \\
\hline
\end{tabular}

Table 7. Archidoris montereyensis. Effect of microalgal fouling on survival and developmental stage of embryos in egg ribbons. Treatments were the 4 combinations of light and dark and seawater with and without nutrient enrichment for algal growth

\begin{tabular}{|c|c|c|c|c|c|c|c|c|c|c|c|}
\hline \multicolumn{4}{|c|}{ Proportion surviving } & \multicolumn{4}{|c|}{ Stage } & \multicolumn{4}{|c|}{ Microalgal fouling (cells $\mathrm{mm}^{-1}$ ) } \\
\hline \multicolumn{2}{|c|}{ Light } & \multicolumn{2}{|c|}{ Dark } & \multicolumn{2}{|c|}{ Light } & \multicolumn{2}{|c|}{ Dark } & \multicolumn{2}{|c|}{ Light } & \multicolumn{2}{|c|}{ Dark } \\
\hline Enriched & Plain & Enriched & Pläin & Enriched & Plain & Enriched & Plain & Enriched & Plain & Enriched & Plain \\
\hline 0 & 0.98 & 0.98 & 1.00 & - & 10.6 & 12.0 & 12.0 & 59 & 60 & 24 & 7.7 \\
\hline 0 & 0.50 & 1.00 & 1.00 & - & 10.5 & 12.0 & 12.0 & 69 & 56 & 2.6 & 3.2 \\
\hline 0.37 & 1.00 & 1.00 & 1.00 & 12.0 & 12.0 & 12.0 & 1.2 .0 & 65 & 57 & 14 & 9.6 \\
\hline
\end{tabular}

\section{Effects of solar radiation}

In laboratory experiments, solar radiation caused embryonic mortality (Table 6) even in the near absence of microalgal fouling. Not only was mortality greater in portions of egg ribbons exposed to a day of solar radiation, the mortality was much greater for embryos on the upper sides of the portions of egg ribbons (Table 6). Thus egg jelly or embryos can shield inner embryos in a thicker egg mass. The depth of water in the experiments was only about $2 \mathrm{~cm}$, but a few of the egg ribbons of Archidoris montereyensis that were deposited on macroalgae were similarly shallow on low ebbing tides and thus exposed to similar solar radiation.

\section{Effects of microalgal fouling}

In laboratory experiments, microalgal fouling was associated with mortality of embryos (Table 7, Fig. 4). This conclusion is based on low replications ( $n=3$ per treatment) because of practical limitations, but the results were striking. Mortality was consistently high in the filtered sunlight with a nutrient enrichment that increased fouling of egg ribbons by diatoms. Some mortality occurred in the filtered sunlight when there was no such enrichment. Nearly $100 \%$ of embryos in the dark survived whether the sea water was enriched or not. Microalgal fouling was greatest with the nutrient enrichment in the light and least in both enriched and unenriched sea water in the dark. With all treatments lumped, the

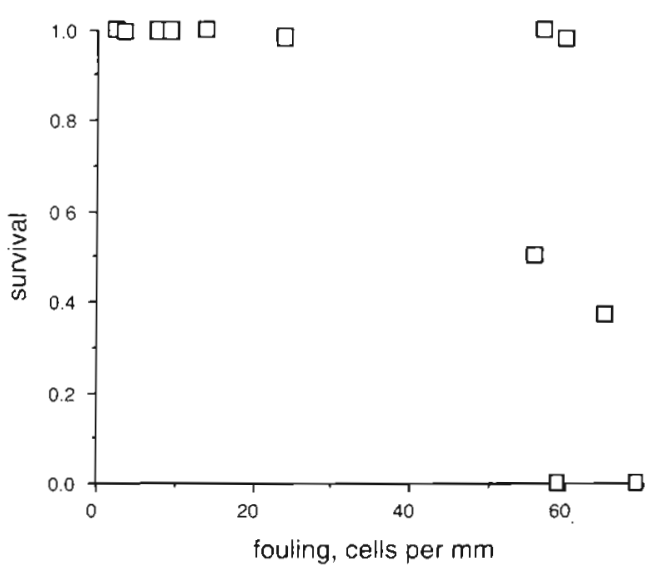

Fig. 4. Archidoris montereyensis. Survival of embryos in relation to microalgal fouling in a laboratory experiment with a glass and acrylic filter for sunlight. Microalgal fouling was manipulated by nutrient enrichment and light levels. The measure of microalgal fouling is number of cells intersected by a transect line

Spearman rank correlation of survival and microalgal fouling was $-0.81(p<0.01,1$-tailed test $)$, and the rank correlation of stage of development and fouling was -0.62 ( $p<0.05,1$-tailed). One cannot reject the hypothesis that the interaction of a stress from nutrient enrichment and a stress from light caused mortality; but because nutrient enrichment did not affect survival or development in the dark, and heavily fouled egg ribbons in the light suffered some mortality even without nutrient enrichment, the simplest hypothesis consistent with the result is that dense 
microalgal fouling retarded development and killed embryos.

In an earlier experiment in the same water cooled trough with the same glass and acrylic filter for sunlight, there was no difference in stage of development and uniformly high survival of embryos after 8 to $10 \mathrm{~d}$ in light or dark. There was no nutrient enrichment treatment, and microalgal fouling in the light reached only 38 cells $\mathrm{mm}^{-1}$ on the most fouled ribbon. This experiment indicates that the filtered solar radiation was insufficient by itself to kill embryos and thereby supports the interpretation that microalgal fouling was the cause of increased mortality in the enrichment experiment.

In a field experiment egg ribbons of Archidoris montereyensis were fouled by microalgae more readily than were glass microscope slides exposed under the same conditions in Argyle Creek for $5 \mathrm{~d}$ (Table 8) (paired sample $t$-test, $\mathrm{p}<0.01$ ). In comparison to the glass slides, the egg ribbons were a favorable habitat for numerous species of diatoms and also for filamentous green algae.

Table 8. Archidoris montereyensis. Microalgal fouling (cells $\mathrm{mm}^{-1}$ ) of egg ribbons and glass slides in Argyle Creek after $5 \mathrm{~d}$

\begin{tabular}{|ccc|}
\hline Replicate pair & Egg ribbon & Glass slide \\
\hline 1 & 40.7 & 8.6 \\
2 & 43.5 & 10.8 \\
3 & 36.7 & 12.3 \\
\hline
\end{tabular}

\section{DISCUSSION}

Egg ribbons of Archidoris montereyensis were preferentially laid at sites in which survival of embryos was high. The preferred sites were under macroalgal cover or other shade, and survival of embryos was greater in the shade. Shading reduced both solar radiation and microalgal fouling of egg ribbons. Either solar radiation or microalgal fouling separately was sufficient to kill embryos in the laboratory. Damage from ultraviolet light has been demonstrated for a variety of planktonic embryos and larvae (Thorson 1964, Damkaer et al. 1981, Hunter et al. 1982). Seasonal increases in solar UV may limit the seasonal occurrence of shrimp larvae in surface waters near Puget Sound (Damkaer et al. 1981), and UV light has been demonstrated to drive vertical migrations of echinoderm larvae near the Friday Harbor Laboratories (Pennington \& Emlet 1986). It is therefore not surprising that solar radiation should kill benthic embryos in shallow water. Heat, desiccation, high or low salinity, predation, and bacteria have been examined as causes of death of encapsu- lated embryos (Pechenik 1986), but previous studies of benthic embryos have not addressed death or stress from UV-light or microalgal fouling.

Initially, we had expected that low current velocity might decrease survival or developmental rates by restricting diffusive supply of oxygen or elimination of wastes, and the division of ribbons for field experiments might have decreased diffusive exchange by increasing layering of the egg ribbon; but the laboratory experiments suggested that ribbons of Archidoris montereyensis have a margin of safety for exchange of materials with the surrounding water, and this margin of safety was confirmed (under the conditions of flow and temperature in Argyle Creek) by the high survival and uniform rates of development in egg ribbons placed in the slower currents beneath macroalgae. However, the thinness that produces a margin of safety for exchange between the embryo mass and the water renders embryos vulnerable to direct damage from solar radiation in shallow water. Also, the surface of the egg ribbon is available to fouling microalgae that can kill embryos when very abundant, perhaps by their depletion of oxygen or addition of wastes at the free surface of the egg mass.

Interactions between solar radiation, microalgal fouling and current speed are likely, though we did not test for them. Faster currents could increase colonization by diatoms. Less sunlight could decrease photosynthesis relative to respiration and hence could decrease a fouled egg ribbon's supply of oxygen. Diatoms could shade embryos from high frequency solar radiation.

Some other shallow water egg ribbons may be less vulnerable to solar radiation and microalgal fouling. Ribbons of the cephalaspidean gastropod Haminoea vesicula Gould are common on upper parts of sea grasses and macroalgae and therefore commonly exposed to full sunlight in shallow water. In preliminary observations, 2 gelatinous egg ribbons of $H$. vesicula were collected from sunny sites in Argyle Creek on 2 July. The embryos in these ribbons were at the veliger stage and had $100 \%$ survival and microalgal fouling of 17 and 39 cells $\mathrm{mm}^{-1}$, which was higher survival and lower fouling than the mean observed for sunlit ribbons of Archidoris montereyensis at that time. These observations of high survival and lower microalgal fouling agree with our impression from many ribbons of $H$. vesicula observed in the field. Ribbons of $H$. vesicula may be better equipped with devices for preventing algal fouling and damage from solar radiation. Diverse means for preventing fouling (Wahl 1989) and for protection against the more harmful frequencies of solar radiation (Hairston 1981, Karentz et al. 1991) are widespread in aquatic organisms. Different defenses of ribbons in different taxa may result in different limitations on suitable sites for egg deposition. 
Estimates of mortality of benthic embryos based on attrition of embryos found in the field may misrepresent costs of benthic development in comparison to planktonic development. The production of capsules (Perron 1981), gel-matrices (Todd 1979) and anatomical modifications for producing these extraembryonic structures deplete the mother's resources but are only part of the costs of protection. Additional costs may be associated with benthic development if adults must expend time and energy travelling to suitable sites or if adults produce fewer egg masses because suitable sites are limiting. For example, S. Cohen, C. Kelley, S. Morgan and J. Schmidt (Friday Harbor Laboratories, unpubl.) increased egg deposition by the cephalaspidean opisthobranch Haminoea vesicula by adding hard substrata to a sand flat where adults were abundant but deposition sites few. DeMartini (1991) increased egg deposition by the fish Porichthys notatus Girard (the midshipman) by increasing unfouled surface area beneath rocks. Perceived risk may inhibit deposition of benthic embryos; Brenchley (1982) found that the mud snail Myanassa obsoleta (Say) dispersed and laid few egg capsules in the presence of a littorine snail that eats the embryos. Dependence on other species can be subtle; Shimek (1981) reported selective deposition of embryos near sea anemones by the snail Neptunea pribiloffensis (Dall) and higher mortality from grazing sea urchins in the absence of the 'baby sitting' anemones. These examples suggest that the need to find and select favorable sites for deposition of embryos may place restrictions on benthic development. Such restrictions are not included in estimates of natural mortality of benthic embryos or the energetic costs of accessory structures. Some animal groups may have planktonic embryos because the parents are less able to circumvent benthic hazards for embryos (Strathmann \& Strathmann 1989). The habitat requirements for benthic embryos and the ability of adults to select favorable habitats combine to restrict benthic development.

Experiments with egg ribbons of Archidoris montereyensis in shallow water in the field and laboratory demonstrate that exposure to the sun can restrict sites for benthic development.

Acknowledgements. This research was supported by NSF Grant OCE8922659 to R. R. Strathmann, by an Austrian Schrödinger Postdoctoral Scholarship to G. O. Schinner, and by the Friday Harbor Laboratories Marine Science Fund scholarships to G. O. Schinner and C. H. Biermann. H. C. Hess and R. B. Emlet commented on the research and an early version of the paper. G. Gibson, R. W. Castenholz, J. Goddard, J. Havenhand, M. Shick and visiting students and scientists at FHL also advised on aspects of the research.

\section{LITERATURE CITED}

Bauer, R. T (1989). Decapod crustacean grooming: functional morphology, adaptive value, and phylogenetic significance. Crustacean Issues 6: 49-73

Brenchley, G. A. (1982). The current status of the 100-year war between native 'mud' snails, Ilyanassa obsoleta, and dominant competitor and predator, the European periwinkle, Littorina Iittorea. Malacol. Rev. 15: 146

Burggren, W. (1985). Gas exchange, metabolism, and 'ventilation' in gelatinous frog egg masses. Physiol. Zool. 58: $503-514$

Conover, W. J., Iman, R. L. (1981). Rank transformations as the bridge between parametric and nonparametric statistics. Am. Stat. 35: 124-129

Damkaer, D. M., Dey, D. B., Heron, G. A., Prentice, E. F. (1981). Effects of UV-B radiation on near surface zooplankton of Puget Sound. Oecologia 48: 178-182

DeMartini, E. E. (1991). Spawning success of the male plainfir midshipman. II. Substratum as a limiting spatial resource. J. exp. mar. Biol. Ecol. 146: 235-251

Fisher, W. S. (1983). Eggs of Palaemon macrodactylus. III. Infection by the fungus, Lagenidium callinectes. Biol Bull. 164: $214-226$

Giorgi, V., Congleton A. (1984). Effects of current velocity on development and survival of ling cod, Ophiodon elongata, embryos. Environ. Biol. Fish. 10: 15-27

Guillard, R. R. L. (1983). Culture of phytoplankton for feeding marine invertebrates. In: Berg, C. L. Jr (ed.) Culture of marine invertebrates. Hutchinson Ross, Stroudsburg, p. $108-132$

Gustafson, K., Andersen, R. J. (1985). Chemical studies of British Columbia nudibranchs. Tetrahedron 41: $1101-1108$

Hadfield, M. G. (1986). Settlement and recruitment of marine invertebrates: a perspective and some proposals. Bull. mar. Sci. 39: 418-425

Hairston, N. G. Jr (1979). The relationship between pigmentation and reproduction in two species of Diaptomus (Copepoda). Limnol. Oceanogr. 24: 38-44

Hairston, N. G. Jr (1981). The interaction of salinity, predators, light and copepod color. Hydrobiologia 81: $151-158$

Hunter, J. R., Kaupp, S. E., Taylor, J. H. (1982). Assessment of effects of UV radiation on marine fish larvae. In: Calkins, $J$. (ed.) The role of solar ultraviolet radiation in marine ecosystems. Plenum, New York, p. 459-497

Hurst, A. (1967). The egg masses and veligers of 30 Northeast Pacific opisthobranchs. Veliger 9: 255-288

Karentz, D., McEuen, F. S., Land, M. C., Dunlop. W. C. (1991) Survey of mycosporine-like amino acid compounds in Antarctic marine organisms: potential protection from ultraviolet exposure. Mar. Biol. 108: 157-166

Lewin, J. (1966). Silicon metabolism in diatoms. V Germanium dioxide, a specific inhibitor of diatom growth Phycologia 6: 1-12

Morse, D. E. (1990). Recent progress in larval settlement and metamorphosis: closing the gaps between molecular biology and ecology. Bull mar. Sci. 46: 465-483

Pawlik, J. R., Kernan, M. R., Molinski, T F., Harper, M. K. Faulkner, D. J. (1988). Defensive chemicals of the Spanish dancer nudibranch Hexabranchus sanguineus and its egg ribbons: macrolides derived from a sponge diet. J. exp mar. Biol. Ecol. 119: 99-109

Pawlik, J. R., Butman, C. A., Starczak, V. R. (1991). Hydrodynamic facilitation of gregarious settlement of a reefbuilding tube worm. Science 251: 421-424 
Pechenik, J. A. (1979). Role of encapsulation in invertebrate life histories. Am. Nat. 114: 859-870

Pechenik, J. A. (1986). The encapsulation of eggs and embryos by molluscs: an overview. Am. malac. Bull. 4: $165-172$

Pennington, J. T., Emlet, R. B. (1986). Ontogenetic and diel vertical migration of a planktonic echinoid larva, Dendraster excentricus (Eschscholtz): occurrence, causes, and probable consequences. J. exp. mar. Biol. Ecol. 104: $69-95$

Perron, F. E. (1981). The partitioning of reproductive energy between ova and protective capsules in marine gastropods of the genus Conus. Am. Nat. 118: 110-118

Rumrill, S. S. (1990). Natural mortality of marine invertebrate larvae. Ophelia 32: 163-198

Shields, J. D. (1990). Rhizophydium littoreum on the eggs of Cancer anthonyi: parasite or saprobe? Biol. Bull. 179 201-206

Shimek, R. L. (1981). Neptunea pribillofensis (Dall, 1919) and Tealia crassicornis (Muller, 1776): on a snail's use of babysitters. Veliger 24: 62-66

Strathmann, R. R. (1985). Feeding and nonfeeding larval development and life-history evolution in marine inverte-

This article was presented by J. S. Pearse, Santa Cruz, California, USA brates. A. Rev. Ecol. Syst. 16: 339-361

Strathmann, R. R., Strathmann, M. F. (1989). Evolutionary opportunities and constraints demonstrated by artificial gelatinous egg masses. In: Ryland, J. S., Tyler, P. A. (eds.) Reproduction, genetics and distributions of marine organisms. Olsen \& Olsen, Fredensborg, p. 201-209

Takano, H. (1985). Symbiotic diatoms in egg-masses of a polychaete. Bull. mar. Sci. 37: 767

Thorson, G. (1964). Light as an ecological factor in the dispersal and settlement of larvae of marine bottom invertebrates. Ophelia 1: 167-208

Todd, C. D. (1979). Reproductive energetics of two species of dorid nudibranchs with planktotrophic and lecithotrophic larval strategies. Mar. Biol. 53: 57-68

Vogel, S., LaBarbera, M. (1978). Simple flow tanks for research and teaching. Bioscience 28: 638-643

Wahl, M. (1989). Marine epibiosis. 1. Fouling and antifouling: some basic aspects. Mar. Ecol. Prog. Ser. 58: 175-189

Wilson, W. H. Jr (1986). Detachment of egg masses of a polychaete: environmental risks of benthic protective development. Ecology 67: 810-815

Woodin, S. A. (1986). Settlement of infauna: larval choice? Bull. mar. Sci. 39: 401-407

Manuscript first received: January 30, 1992

Revised version accepted: August 18, 1992 